This item was submitted to Loughborough's Research Repository by the author.

Items in Figshare are protected by copyright, with all rights reserved, unless otherwise indicated.

\title{
Creative 'tips' to integrate human factors/ergonomics principles and methods with patient safety and quality improvement clinical education
}

\section{PLEASE CITE THE PUBLISHED VERSION}

https://doi.org/10.1007/978-3-319-96098-2_14

\section{PUBLISHER}

(C) Springer

VERSION

AM (Accepted Manuscript)

\section{PUBLISHER STATEMENT}

This is a pre-copyedited version of a contribution published in Bagnara, S. ... et al. (eds.) 20th International Ergonomics Association (IEA2018): Volume IX: Aging, Gender and Work, Anthropometry, Ergonomics for Children and Educational Environments published by Springer. The definitive authenticated version is available online via https://www.springer.com/us/book/9783319960647

\section{LICENCE}

CC BY-NC-ND 4.0

\section{REPOSITORY RECORD}

Vosper, Helen, Sue Hignett, and Paul Bowie. 2019. "Creative 'tips' to Integrate Human Factors/ergonomics Principles and Methods with Patient Safety and Quality Improvement Clinical Education”. figshare. https://hdl.handle.net/2134/35060. 
Vosper, H., Hignett, S., Bowie, P. (2018) Creative 'Tips' to integrate HFE principles and methods with patient safety and Quality Improvement clinical education. Proceedings of the $20^{\text {th }}$ Triennial Conference of the International Ergonomics Association. Florence, Italy, 26-30 August.

\title{
Creative 'Tips' to integrate Human Factors/Ergonomics principles and methods with patient safety and quality improvement clinical education
}

\author{
Helen Vosper ${ }^{[0000-0001-7796-5183]}$, Sue Hignett ${ }^{[0000-0002-3025-7451]}$ \\ and Paul Bowie ${ }^{\text {[0000-0001-6027-2559] }}$ \\ ${ }^{1}$ Robert Gordon University, Aberdeen, UK; \\ ${ }^{2}$ Loughborough Design School, Loughborough University, UK; \\ ${ }^{3}$ Medical Directorate, NHS Education for Scotland, Glasgow, UK; \\ h.vosper@rgu.ac.uk; S.M.Hignett@lboro.ac.uk
}

\begin{abstract}
The goal of these 12 tips is to enhance the effectiveness of safety and improvement work in frontline healthcare practice by providing a framework for integration of Human Factors and Ergonomics (HFE) theory and approaches within undergraduate curricula, postgraduate training and healthcare improvement programs. This paper offers both support and challenges to healthcare educators when planning the inclusion of HFE principles within existing curricula. The 12 tips include the systems framework (Tip 1, 3), HFE tools and competency (Tips 2, 7), misunderstandings (Tips 4, 5), and ideas for implementation (Tip $6,8,9,10,11,12)$. They will support the goal of enhancing the performance of care systems (productivity, safety, efficiency, quality) and the wellbeing of all the people (patient outcomes, staff presenteeism).
\end{abstract}

Keywords: Education, Competency, Accreditation

\section{Introduction}

There is an increasing focus on safety in healthcare education but progress is slow with little direction for teaching provided by professional, statutory and regulatory bodies. The World Health Organisation [1]developed a patient safety curriculum, but little is known about integrating Human Factors and Ergonomics (HFE) concepts.

This paper outlines 12 tips [2] to provide a preliminary platform for healthcare educators to explore how to integrate key HFE principles within existing curricula. The tips include the systems framework (Tip 1, 3), HFE tools and competency (Tips 2, 7), misunderstandings (Tips 4, 5), and ideas for implementation (Tip 6, 8, 9, 10, 11, 12) with the knowledge sequence indicated in figure 1 . We believe that these tips will support the goal of enhancing the performance of care systems (productivity, safety, efficiency, quality) and the wellbeing of all the people (patient outcomes, staff presenteeism). 


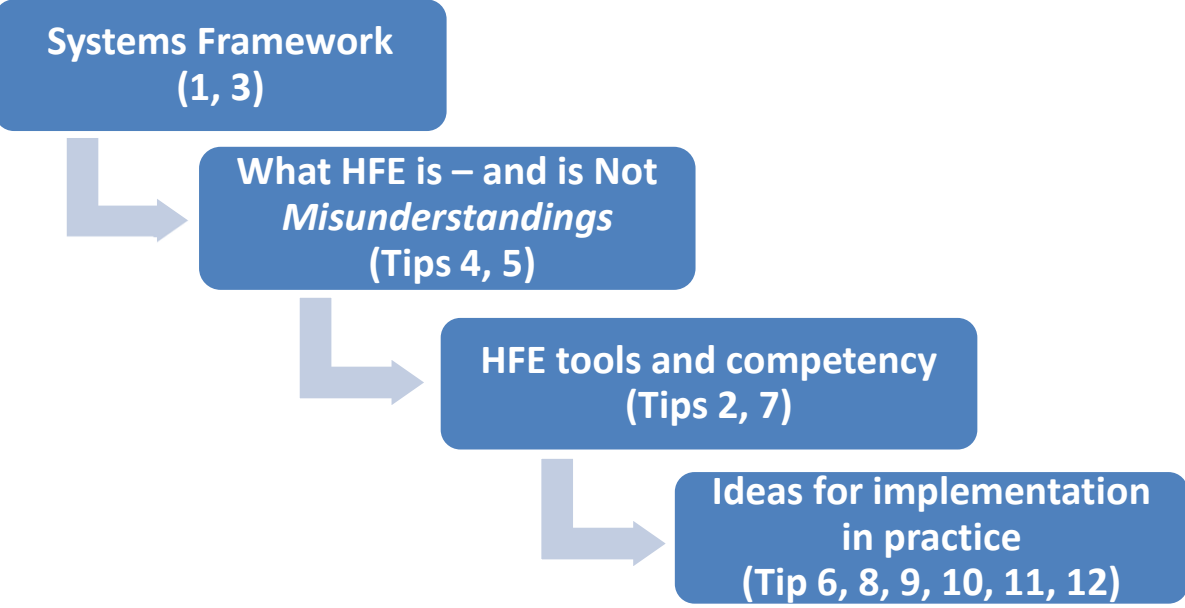

Fig. 1. Four general categories for 12 Tips

\section{$2 \quad 12$ Tips}

\subsection{Tip 1: Jointly optimise systems performance and human wellbeing}

The HFE core concept is to jointly optimise systems performance and the wellbeing of people. Understanding and applying the systems approach must be the starting point for embedding HFE; it is a fundamental HFE concept and underpins all the other tips. Systems are defined as " $a$ set of inter-related or coupled activities or entities (hardware, software, buildings, spaces, communities and people) with a joint purpose”. There needs to be an increased focus on Safety-II to optimise overall systems performance and human wellbeing

- Safety-I is an error-reductionist approach which seeks to identify and rectify the root cause(s) of 'errors' and often focuses on people (e.g. technique training) rather than wider systems when trying to understand and resolve issues

- Safety-II recognises that systems, despite their inherent imperfections, operate safely most of the time (through resilience adjustments, Tip 9)

\subsection{Tip 2: Teaching faculty}

Teaching faculty must be competent to deliver theory and practice (knowledge and skills). A minimum HFE competency (see Tip 7) is needed for appropriate application of HFE tools (including systems modelling and task analysis) and interpretation of results. 


\subsection{Tip 3: Consider adopting human-centred organisation principles}

Practice what you preach: consider adopting human-centred organisation principles.

- Address the hidden curriculum/culture where the safety values and attitudes are more influenced by implicit learning from in-practice behaviours than from taught curricula.

- In other sectors, international standards are used to ensure products and services are of appropriate quality

\subsection{Tip 4: Recognise what HFE is...}

Recognise what HFE is... A specific way of thinking and doing which needs to be fully embraced if benefits are to be realised. Healthcare systems range from micro systems (single tasks/tools) through meso systems (teams), up to complex (macro) systems. HFE interventions may focus on optimisation of a micro-system, but there will always be clear mapping of the relationship of the micro with the macro system. Incorporate HFE from project inception across micro, meso and macro systems

\subsection{Tip 5: ...And recognise what HFE is not}

HFE is not behaviour-based training and rarely identifies a single "root cause" after a systems analysis. An HFE intervention would not focus on requiring people to adapt behaviours (non-technical/specialist skills) to accommodate poorly designed systems of work and/or technology

\subsection{Tip 6: HFE and QI synergies}

Don't throw the baby out with the bath water: Recognise that HFE and QI can offer synergies. Explore a combined HFE and QI approach for real-life problems to inform more meaningful design and evaluation of improvement interventions.

- HFE focusses more on wellbeing and performance

- QI focusses more on process issues; the processes are mostly delivered by people but the people are not the focus of the improvement

\subsection{Tip 7: Three levels of HFE competencies}

Curriculum design and content should be driven by learning outcomes to develop appropriate HFE competencies. Signpost HFE competency to support professional practice within a code of conduct (IEA) and additional education 


\subsection{Tip 8: Participatory approach}

Use the participatory approach central to HFE to strengthen your specific curriculum or programme of training. Provide space to actively promote recognition of mismatches; this requires partnership with staff/students ('experts' about the hidden curriculum).

\subsection{Tip 9: Learning from errors}

Recognise that to err is not just human, but is highly desirable as part of a learning strategy to develop transferable skills in building resilient systems. It is not possible to prevent all errors (normal part of work and learning) in complex sociotechnical systems. A zero-error approach to patient safety is the least effective approach. Need opportunities to consider safety in day-to-day routines and the systems resilience to absorb inevitable errors and deliver outcomes. Exploring factors that reduce/prevent risk requires educational-based opportunities to make errors and follow the trajectory to the natural end.

\subsection{Tip 10: Build on what is already there}

Build on what is already there. Many curricula may have 'human factors' teaching, even if it is focussed on 'non-technical skills' (see Tip 5) or 'patient safety' training. Review whether content includes the HFE fundamental principles in collaboration with HFE experts from IEA Federated Societies.

\subsection{Tip 11: Inter-Professional Education}

Take an Inter-Professional Education perspective to curriculum design and content. Systems optimisation can only happen if all relevant stakeholders are engaged. Consider 4 groups for HFE interventions:

- Systems actors: healthcare staff, patients (service users), carers etc.

- Systems experts: including HFE professionals

- Systems decision makers: e.g. managers, with power to effect change

- Systems influencers: political bodies, regulators etc.

\subsection{Tip 12: HFE capacity and capability}

Build HFE capacity and capability creatively. The following ideas can be considered:

- Input from qualified and regulated HFE professionals to ensure both credibility and that professional standards are adhered

- Build collaborations with other healthcare disciplines to enrich the expert pool

- Train healthcare staff with postgraduate academic training to be HFE “champions" with responsibility for supporting others in HFE practice and educational provision 
including developing "train the trainer" activities to support basic competency with fundamental concepts and approaches that can be applied in frontline care

- Develop HFE expertise by setting objectives within existing reward and recognition frameworks for current healthcare teaching and learning, and at postgraduate level through CPD activity

\section{Conclusion}

An important opportunity exists for current undergraduate curricula, postgraduate training and healthcare safety and improvement programs to be considerably strengthened by the integration of HFE theory and methods. While current guidance for patient safety teaching appears to recognize this, it is apparent that the potential impact is compromised by conflation of HFE and a limited and potentially misleading focus on "factors of the human." The WHO multiprofessional patient safety curriculum [1] (for example) is one of the few resources available to healthcare faculty for designing and delivering curricula that support the development of safety competence. While this document contains a great deal of excellent guidance, its practical application is perhaps undermined by an apparently conflicted understanding of HFE.

\section{References}

1. WHO. 2011. World Health Organisation The Multi-Professional Patient Safety Curriculum Guide. http://www.who.int/patientsafety/education/curriculum/en/ [accessed 15 June 2017]

2. Vosper, H., Bowie, P., Hignett, S. (2017) Twelve tips for embedding Human Factors and Ergonomics principles in healthcare educational curricula and programmes Medical Teacher doi.org/10.1080/0142159X.2017.1387240 